\title{
Creating Information Retrieval Competence of Future Translators: An Integrative Approach
}

\author{
Anna Gureeva \\ Department of Translation Theory and Practice, Volgograd State University, 400062 \\ Prospect Universitetsky 100, Volgograd, Russian Federation; Email: poddubnova.anna@mail.ru \\ Svetlana Korolkova \\ Department of Translation Theory and Practice, Volgograd State University, 400062 \\ Pr. Universitetsky 100, Volgograd, Russian Federation; Email: svetlanakrlkvavlg@yandex.ru
}

\section{Anna Novozhilova}

Department of Translation Theory and Practice, Volgograd State University, 400062 Pr. Universitetsky 100, Volgograd, Russian Federation; Email: novozilova@yandex.ru

\section{Evgenia Shovgenina}

Department of Translation Theory and Practice, Volgograd State University, 400062 Pr. Universitetsky 100, Volgograd, Russian Federation; Email: shovgenina@mail.ru

Vera Mityagina

Department of Translation Theory and Practice, Volgograd State University, 400062 Pr. Universitetsky 100, Volgograd, Russian Federation; Email: mityagina@mail.ru

\author{
Doi:10.5901/mjss.2015.v6n6s5p78
}

Abstract

This article deals with information retrieval competence in translation teaching and shows its importance for optimizing work of the future interpreters and translators in the modern globalised labor market. The goal of the article is to provide the authors' view on the didactic aspect of training information retrieval activity to the future interpreters and translators and present the course 'Information Retrieval in the Work of a Translator' developed by the group of authors in the Translation Studies Department at Volgograd State University, Russia, introduced into the educational process. The article gives a detailed view of the course and its structure showing and explaining the main aspects of the training process and the results obtained. The advantages of the course are discussed in respect with the necessity to form skills and abilities necessary for translation as well as developing individual abilities of the students. The article concludes by emphasizing the significance of the integration of the course 'Information Retrieval in the Work of a Translator' with the practical courses of translation and interpretation and seminars in the translation theory and methodology, which promotes creation of professional translation competence and expansion of the general existential competence of future interpreters and translators.

Keywords: interpreting, translation, intercultural communication.

\section{Introduction}

The competence-based and personality-oriented higher education is to be aimed at creating the appropriate conditions for mastering knowledge, skills and abilities in practice, rather than at merely transferring them. The content of training should be focused on forming professionally significant competences, on developing great erudition of the students as well as such personal qualities as ability to reflection, i.e. analysis and generalization, readiness to overcome stereotypes and at the same time obligatory developing of the aspiration to self-training. Nowadays any expert's professional activity assumes complex and variable use of both theoretical knowledge and practical abilities, while every professional task is interdisciplinary and integrative; so an expert is required to apply the system analysis in order to find the model of its 
solution, therefore, the integrative approach is supposed to be implemented in professional higher education. Interdisciplinary integration will provide systemacity and consistency of knowledge, experience, skills, as well as intensification of their mastering and, as a result, will create readiness and ability of the students to efficient activity in various situations and, therefore, their competitiveness in labor market (Korol'kova, 2013, 93).

Today's globalization results in strong influence of electronic and computer technologies on all spheres of human activity that leads to distribution of information streams in society and forms a common information space. It has a significant impact on translation business; as well as it constantly assigns new tasks to modern translators and makes more and more strict demands to their work. In the third millennium, translators' activity is inconceivable without new information technologies and electronic tools aimed at accelerating and simplifying a translation process. They include electronic multilingual translated and monolingual explanatory dictionaries; automatic machine translators (software products of the PROMT company and the Google.Translate service are best known in Russia); Translation Memory systems (TRADOS, Deja vu, etc.); texts editing programs; electronic libraries; electronic encyclopedias; terminology databases and the global Internet itself as a storage of highly improbable volume of information resources.

Proficiency in applying above-mentioned and other electronic means enable translators to optimize their work as well as increase their competitiveness in the translation services market. As V.N. Shevchuk, the author of one of the most interesting and considerable works in this sphere, notes, 'electronics is not in the least a whim, not a craze and not an idle toy in hands of the person. It is considered as dictates of the present time and vital necessity. After all, now it is almost impossible to imagine a professional translator who does not apply in a varying degree electronic means, does not handle a computer properly, or printer and scanner and does not use e-mail and special programs focused on translation needs' (Shevchuk, 2010, 6).

\section{Current State of the Problem}

Now information retrieval skills and abilities of a translator, or his/her information retrieval competence, as well as skills of using information driven technologies in the process of interpretation and translation (i.e. information and technological competence) are discussed vigorously by translation scientists and translation teachers of the higher school. There have been many research papers on information retrieval emphasizing its significance for the translation. $\mathrm{H}$. Ahrens wrote about importance of the Internet for translators as early as in 1999; she distinguished the following areas of using the Internet in translation practice: searching for and obtaining the orders, communicating with colleagues, public relations and information retrieval (Ahrens, 1999, 25-47). L. Lagarde in his doctoral dissertation provides the results of the professional translators' poll concerning their information search preferences: a vast majority prefers the Internet sources; consultations with experts rank second; as for traditional print sources (books, dictionaries, reference books, etc.) they take the "modest" third place. The arguments in favor of consulting Internet sources include convenience of use, availability in any place at any time, necessary for the translation, up-to-dateness and regularity of updating (Lagarde, 2009, 39-43).

Gradually the translation and interpreting studies specialists began to be interested in the didactic aspect of information retrieval, namely training information retrieval activity for the future translators. E.J. Ammour gives an example of worthwhile experiment of the leading European translation school of the University of Paris III: Sorbonne Nouvelle, (ESIT) on training information search for the future translators both in the mode of consultations with experts, as well as using only Internet resources. The paper provides algorithm of the students' reflection about the course of information search and estimation of the obtained results, which is very interesting from the methodical point of view (Ammour, 2005, 85-94).

As $\mathrm{H}$. Schüßler emphasizes, the Internet is actively used by experts of different spheres for professional purposes and it is hardly possible to imagine the translators who do not use the Internet to search for information (Schüßler, 2012, 1). The author calls the Internet a source of macrosearch and offers the detailed concept on developing Internet and search competence while training professional translators; she describes search techniques and search strategies necessary to train students of the translation programs. According to S. Göpferich and P. Kußmaul, internet resources that help to rationalize and optimize the work with the terminology, terminological data banks are of great significance, especially if they have the advantage of quick updating and constantly adding new terminology (Göpferich, 2007, 428 and Kußmaul, 2010, 29).

$\mathrm{U}$. Muegge claims 'Offering translation technology courses is easier than it ever was: Cloud-based learning management systems and translation management systems offer educational institution the powerful tools they need to prepare future translation and localization professionals for the demands of the 21st century'. At the same time he compares the teacher of the past and present, as well as he speaks of the possibility of reducing the number of 
educational software systems to two: an integrated learning management system and an integrated translation management system, thus the instructors can teach a maximum number of skills with a minimum number of tools (Muegge, 2013, 137-146).

All the above-mentioned works indicate that the specified competences are the integral component of professional translation competence. At the same time the importance of sophistication in their formation for the future translators constantly intensifies; the higher education institutions graduating translators should provide and develop the courses, which will help students become acquainted with such technologies and tools and train to work with them. Moreover, such courses have to provide interdisciplinary integration of theoretical and practical profession-focused disciplines. The maximum focus of the education on formation of the professional competences necessary in real process of rendering translation services is an indispensable condition of training the translators who conform to the requirements of modern information-oriented society and modern labor market.

\section{Research Objectives and Methodology}

The aim of our paper is to reveal and present the strategies to form the students' skills of working with information resources and retrieval systems necessary for their professional activity as means of translation quality control and translation process optimization. To fulfill this aim we need to set and reach the following goal:

To create and present the complex of tasks and exercises for students to form their information retrieval competence, in particular, the students' ability to collect necessary information and elevate their background of knowledge; an ability to find information needed for adequate translation of the source text; an ability to develop a strategy to resources retrieval and their quality assessment to solve the translation tasks; an ability to get the most out of information resources collected.

To approve the results achieved we present in this paper the course 'Information Retrieval in the Work of a Translator' and provide a detailed description of it applying the following methods:

- present and describe the basic elements of the course,

- reveal the correlation between the course presented and the other disciplines taught in the 3rd year of the bachelor degree program, (code and name) 45.03.02 'Linguistics', profile 'Translation and Translation Studies',

- description of the authors experience of the course teaching.

\section{Results and Discussion}

\subsection{Developing the Information Retrieval Competence of the Translator}

Relevant requirements to the higher education results in the conditions of information-oriented society making the teachers focus on training the specialists possessing the information retrieval and information and technological competences as well as skills of solving professional tasks based on them. After having mastered the training program, future translators have to possess the following all-professional and professional competences:

- skills of working with the computer as an instrument of receiving, processing and managing information;

- ability to work with various data carriers, distributed databases, as well as with global computer networks;

- ability to work with electronic dictionaries and other electronic resources to solve linguistic tasks;

- ability to apply standard procedures of searching, analyzing and processing research material;

- ability to apply a procedure of preparing for translation, including information search in reference and special books, as well as computer network;

- skills to process and format a target text using a computer text editor.

Realizing the significance of this component of the professional translation competence and aiming at training the high quality expert relevant in the translation services market the group of authors in the Translation Studies Department at Volgograd State University developed and introduced the course 'Information Retrieval in the Work of a Translator' into educational process. This discipline is taught in the 3rd year of the bachelor degree program, (code and name) 45.03.02 'Linguistics', profile 'Translation and Translation Studies' with the aim of forming and developing the following components of translator's professional competence: cognitive, i.e. awareness of need of information search to understand and translate a text adequately; strategic, i.e. ability to collect necessary information; technical, i.e. ability to use information resources effectively; critical, i.e. ability to estimate reliability of information sources and obtained 
information (Novikova, 2012, 80); and heuristic, i.e. abilities to identify the encountered problem, to formulate correctly a retrieval request as well as to limit area and volume of search within necessary and sufficient information.

As mentioned before, the main objective of training future translators is to train the specialists meeting the requirements of modern information society and modern labor market with professional competence corresponding to real conditions of rendering translation services and enabling to adapt and join quickly to the professional environment. Integration of the course 'Information Retrieval in the Work of a Translator' with the practical courses of translation and interpretation and seminars in the translation theory and methodology allows us not only to make the studies interesting, practice-focused, but also to provide necessary integration of theoretical knowledge with practical abilities and skills. The course is divided into three blocks: the first two are instructional; the last one is practice-focused, aimed at real information retrieval for specific translation situation. The thematic representation of the final block is determined by the content of the interpreting and written translation courses. The teacher of this very discipline, in fact, executes an 'order' for lessons in Interpreting and Written Translation and works closely with teachers of the mentioned disciplines.

\subsection{Organizational aspects of information retrieval activities}

The organizational block in spite of obviousness and evidence of its themes (how to organize translator's working space; stages of preparing for translation and interpretation; the basic rules of ordering and formatting, stipulating price and delivering the translation) proved to be a significant stage for reconsideration by students of their working tool, i.e. the computer, which became already an integral element of their vital space. In this block, we focus attention to the organizational moments of translator's professional activity obvious to the working translator and not so obvious to a student facing for the first time professional requirements imposed on both the translator and the text.

For the third year students it is important to have the tasks and requirements facing the professional translator to be designated, formulated since they have not obtained practical professional experience yet.

Since our 21 century is a century when most of translators work from remote access, then rules of Internet communication with the employer must be familiar and clear to the students. Particular attention should be paid to such seemingly obvious moments as a decent and appropriate e-mail address, the subject in the letter, the name of the file, etc. In real life, the potential employer can sometimes come to bewilderment and confusion concerning 'strangeness' of e-mail addresses as we teachers are confused and embarrassed, when our students send us their translated texts to be checked. To illustrate it we will give some examples of such not quite appropriate addresses where funny, odd and sometimes ridiculous nicknames are used: malinka-natashka@...., kalin-malin@...., pro100ksusha@..., cherry-verry@...., saltyjohnny@..., vostorgforever@....

Moreover, it is necessary to discuss with students such aspects of communication with the employer as sending the executed order by e-mail. Besides, we have to point to inadmissible defects: sending files by e-mail without subject of the letter, incorrect name of the file or besides the 'strange' name. It seems that such things are obvious and everybody has to understand them, but experience of teaching translation and this discipline shows that it is significant to explain and clarify all necessary issues from the very first class both in the Translation, and in Information Retrieval, and to demand their observance not only at the Information Retrieval lessons, but also at Practice of Translation and Interpretation. Therefore, the teacher makes future translators acquainted with these basic rules of composing and formatting the translated text; together with the teacher of Translation demands their strict observance and organizes simulation of real conditions of translating.

It is also essential that during the lesson students could have an opportunity to express and exchange their own experience of using various technologies and tools, including even such parameters as the price and quality. Now most of students use smartphones and tablets, so it is very useful to discuss even their advantages in particular for translators, and highlight important parameters and features that are installed on these devices.

The last task of the organizational block is to prepare review of the most known Russian and foreign search engines, revealing their distinctive features, advantages and shortcomings (Google, Yandex, Yahoo, etc.). As a rule, students undertake this task with pleasure because it is a fine opportunity for them to show the knowledge in this sphere and other technical competences, for example, to prepare interactive presentation of advantages and disadvantages of some search engine.

\subsection{Systematization of knowledge about the Internet}

The information block is aimed at formation of specific experience and skills of information retrieval on the Internet. During our training, we focus our students on developing practical skills of preparing to interpreting and translation in the 
conditions of the maximum approach to realities of translation activity. Within this block, it is necessary to systematize students' knowledge on Internet space. The best thing is to begin with discussion of typology of the existing sites: reference sites (dictionaries, encyclopedias, glossaries, terminology databases, etc.); presentation sites (sites of enterprises, organizations, governments, international and public organizations, labor unions, etc.); specialized sites (linguistic, translation, etc.); personal sites (blogs, etc.). Moreover, to specify what information can be found mainly on each type of the site, what criteria of an assessment of site quality and the rule of verification of the obtained information.

In the information block special mention should be made of the most popular translation tools, namely translated dictionaries. The students have to master the knowledge and skills that are essential to work with these resources: to get acquainted with various types of electronic dictionaries, with the principles of creation of entries in different dictionaries, to learn how to evaluate critically available electronic lexicographic sources and to make a right choice. Within 'Information Retrieval in the Work of a Translator' the students should be taught to distinguish the advantages of working with the electronic dictionaries in comparison with the print versions, i.e. easy access, convenience of work, high speed of information searching and processing, fast pasting of translation equivalents to a target text, etc. However, one can mention some shortcomings e.g. having made up vocabulary very fast the authors and editors often do not manage to verify all dictionary definitions. In particular, it concerns such dictionaries to which the registered users can add their own comments and variants of translation. Therefore, when choosing translation equivalents it is necessary to teach students not to rely only on dictionaries and their own intuition, but to address to other resources to verify suitable equivalents of the translation. The students should be taught to assess the efficiency of different dictionaries according to the following criteria: the time consumed, availability of necessary terms and thematically focused words, as well as examples for checking lexical collocation, evidence of lexicon belonging to a certain subject or scientific domain, etc. During completing the tasks relating to the last (practical block) when searching translation equivalents in dictionaries it is a good practice to compare various dictionaries in order to provide students with the opportunity as early as during the training in higher education institution to elevate mind and develop their own opinions on the electronic lexicographic sources.

The following tasks refer to the "strategic" component: determining the algorithm of preparing for translation and interpretation. The algorithm of information retrieval involves, first of all, understanding the search purpose (expansion of background knowledge of required subjects to sufficient level; making up personal corpus of the required subjects both monolingual, and bilingual; revealing the conventions of the text; lexical search; checking the translation equivalents, etc.) and the type of required information (thematically focused texts; texts of a certain type and genre; searching for translation equivalents for an abbreviation, word, phrase, etc.).

As for search principles, it is important to show the 'nuances' familiar to the practicing translators, i.e. to formulate retrieval request correctly without forgetting about filters: having restriction on language, for example google.fr or google.de, or using specific language elements in the retrieval request line, which help not to leave the space of the required language. When searching in the French or German languages, for example, it is recommended to use an article, an element that prevents from passing into English-speaking Internet space if the retrieval request has any lexical units similar to their English equivalents. The students often do not know technical components of a retrieval request, for example, quotes, asterisks and other symbols.

\subsection{The integrative approach to the practice of information retrieval}

Technological block is a block of interrelated lessons providing the development of the knowledge, skills mentioned above. Its practical focus is essential for the success of this course: any task is to be connected with real need for this information in order to complete educational activity. The teachers of Information Retrieval and Practical Course of Translation and Interpreting must work in a close contact. The information obtained at the classes in Information Retrieval is to be used at Translation and Interpretation classes and assessed by the teacher.

This discipline is taught in the 5th semester, when the students start to study translation disciplines Practical Course of Translation and Practical Course of Interpreting. The students are trained Interpreting within standard communicative situations of working with a foreign delegation, as for Translation, they are trained on the examples of standard genres and types of texts of business communication, therefore, providing integration of three disciplines. That is why one of the themes of this block is Enterprise Information in the Russian language and a foreign language: searching the sites, their verification.

The preliminary tasks can be formulated as follows:

1. Find information on what enterprise is (in Russian, then in a foreign language).

2. Does information in a foreign language corresponds completely to information in Russian.

As emphasized in our work, the tasks should be of practical character and relevant during the classes in the 
practical Translation (oral or written). The results of the task stated above (coordinated and considered together with teachers of Interpreting and Translation) allow the students to optimize the process of translation and interpretation as the general background knowledge of students is brought to necessary and sufficient level.

Discussion of translating the ownership forms abbreviations is very useful. Not only students, but also professional translators face a problem of translating the names of ownership forms and abbreviations of various enterprises. Many students independently find very good information on what rules are necessary to be observed to translate an abbreviation of a Russian enterprise ownership form into a foreign language and vice versa. The knowledge acquired while carrying out this task will be useful both during the classes in Interpreting and Translation, and in professional activity.

Another issue of discussion is the problem of verification of the web sites, with extensions as an important part of domain names, countries. Students, perfectly knowing that the English and French languages are not only languages of Great Britain, the USA and France respectively, but also languages which are spoken in European, African, Asian and Latin American countries, seldom think that when searching, for example, interpretation and explanation of an abbreviation, it is necessary to pay attention to the country of the site location. So, only when the teacher draws the students' attention to the fact that the extension 'ca' in case of French refers to Canada, and 'be' to Belgium and, therefore, the same abbreviation can have various interpretations, students realize the significance of such extensions in the web site address. The same concerns the German-language sites at which the de extension indicates belonging to Germany, and the .at extension to another German-speaking country - Austria. However, the professional translator always has to remember and focus on the following: resident of what country is the sender of the text and for recipient of what country the translation is carried out.

With reference to formation of skills and abilities in applying information retrieval technologies in the field of translation, the theme of the lesson can be formulated as follows International commercial terminology: Incoterms, translation of commercial terms and abbreviations as well as parallel or analog texts of the commercial documents: samples of commercial documents (bill of lading, invoice and draft or bill of exchange in foreign language and in Russian.

The tasks can be formulated as follows

1. Identify the main abbreviations used in business correspondence, and offer their equivalents. Make up the list of the main abbreviations used in business correspondence (the list of abbreviations depends on the language learned).

2. Find explanation and interpretation of the basic terms of delivery used in the contracts: Ex-Factory, Ex-Mill, Ex-Works; Ex-Store; Ex-Stock; FAS; FOB; FOR; FOT;FOC; FOB Airport; C\&F, CAF; CIF; FRC; DCP; CIP.

The students easily cope with such tasks; actively discuss the results on obtained information during the lessons, thus, expanding their background knowledge.

It is useful to teach students to form their own stock of pattern texts and a parallel text corpus on translation for future professional activity. As the teacher conducting classes in Information Retrieval works in close contact with teachers of Interpretation and Translation, the list of themes and tasks remains open and varies depending on real requirement. Relying on our own experience, it is possible to give the following themes for discussion as an example:

- Searching the equivalents of positions: information retrieval on the sites and work with online dictionaries (bilingual monolingual);

- Searching and translating toponyms.

- Proper names translation rules: transcription, voice online programs;

- Latin expressions in native and foreign languages (business and official register).

At the end of this course, the students are offered to make a sitography relevant for professional activity. Essential condition is considered to be a common 'collection' of the sites, which all members of this group can use.

\subsection{Independent Work}

It is obvious that classroom work will not give necessary effect without independent work; therefore, its volume must be considerable. We believe, the project work is the most effective form as it allows a student to demonstrate his/her own abilities and the acquired knowledge as well as the developed skills. The independent work must be a considerable component of the final evaluation for the discipline.

To get credit during the last class the student has to present and defend the project work. The evident advantage of exchanging the experience of information retrieval during our classes is also worth mentioning. It is obvious that the teacher having considerable experience of translation and retrieval can give a lot to the students in the course of 
classroom work, but as it was already noted above, many modern students are very advanced users, including the Internet and various interesting and useful resources optimizing work of the translator. Thanks to such students, the classes practically always take place in the atmosphere of beneficial interaction that is certainly meaningful.

\section{Conclusion}

This paper considers information retrieval competence in translation teaching and confirms its pivotal role in making the work of the future interpreters and translators efficient. The students' ability to realize the necessity of information retrieval for a deeper sufficient understanding of the source text is an important component of professional competence. During information retrieval process the students must work with various resources which makes it necessary to know the proper way to choose and "filter" the right and reliable information resources. The multiple character of information retrieval competence proves its considerable contribution into the formation of the translator/interpreter's professional competence and confirms the need for a didactic approach to this problem. We think that particular attention must be focused on the formation of information retrieval competence in teaching translation and interpreting.

Thus, this course Information Retrieval in the Work of a Translator' developed by the group of authors in the Translation Studies Department at Volgograd State University, Russia, is one of the instruments of forming skills and abilities necessary for translation, as well as developing individual abilities. Its indisputable advantages include practiceoriented approach while having the necessary set of theoretical knowledge in various spheres of human activity, as well as the integrated character that, certainly, promotes development of professional translation competence, but the most important is that it is focused on development of the personality of any student, promotes expansion of the general existential competence of future translators. The role of the teacher is very important: he/she has to formulate correctly questions and issues, which will make students look for not ready answers or solutions, but carry out the intellectual operations allowing to receive required, sometimes unexpected result.

\section{References}

Ahrens, H. (1999). Der Translator im Dschungel des Internet. Oder: Pfadfinderausbildung für Translatoren?. TextconText - Zeitschrift für Translation, Theorie, Didaktik, Praxis, H.13. NF 3., 24-47.

Ammour, E.J. (2005). La recherche documentaire dans l'enseignement de la traduction. La Théorie interprétative. V. III De la Formation à la pratique professionnelle. Lettres modernes minard, Paris - Caen, 3, 85-94.

Göpferich, S. (2007). Computer-Aided Terminology Work at the Department of Translation Studies of the University of Graz. Interdisciplinary Aspects of Translation and Interpreting / Interdisziplinäe Aspekte des Übersetzens und Dolmetschens. Hrsg. Judith Murath und Agnes Olah-Hubai. Wien: Praesens, 425-432.

Korol'kova, S.A. (2013). Integratsionnyj podkhod k professional'noj podgotovke perevodchikov v evropejskikh vuzakh [Integrative approach to the professional training of translators in European institutions of higher education]. Izvestiya Saratovskogo un-ta. Nov. seriya. Ser. Filosofiya. Psikhologiya. Pedagogika, 4, 92-96.

Kußmaul, P. (2010) Verstehen und Übersetzen. Ein Lehr- und Arbeitsbuch. 2. aktualisierte Auflage. Tübingen: Narr (NarrStudienbücher).

Lagarde, L. (2009). Le traducteur professionel face aux textes techniques et à la recherche documentaire. Linguistics. Université de la Sorbonne Nouvelle - Paris III. French.

Muegge, U. (2013). Teaching computer-assisted translation in the 21st century. In Ende, Anne-Kathrin; Herold, Susann; Weilandt, Annette (Eds.), Alles hängt mit allem zusammen: Translatologische Interdependenzen. Festschrift für Peter A. Schmitt, Berlin: Frank \& Timme. 137-146.

Novikova, E.Yu. (2012). Informatsionno-poiskovaya kompetentsiya v paradigme perevodcheskikh kompetentsij [Information retrieval competence in a paradigm of translation competences]. Vestnik Volgogradskogo gosudarstvennogo universiteta. Seriya 6 : Universitetskoe obrazovanie, Volgograd: VolGU, 13, 78-83.

Schüßler, H. (2012). Wer suchet, der findet? Die Vermittlung von Internetrecherchekompetenz in der Übersetzerausbildung. Verlag Dr. Kovač, Hamburg, 172.

Shevchuk, V.N. (2010). Elektronnye resursy perevodchika: Spravochnye materialy dlya nachinayushhego perevodchika [Electronic resources for a translator: references for an aspiring translator]. Moskva: Librajt, 136. 